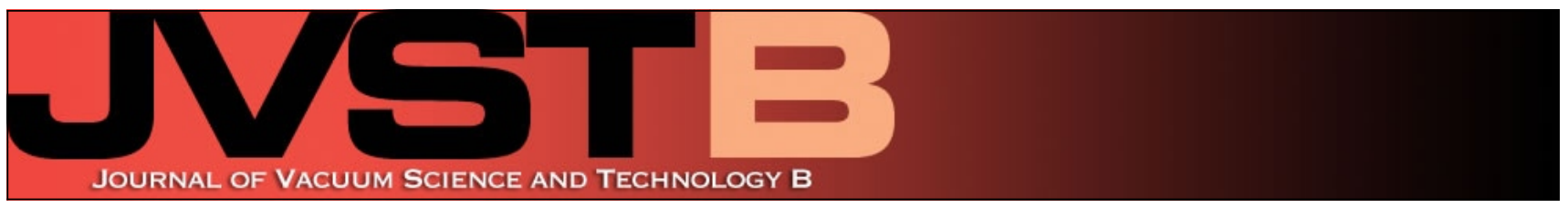

\title{
Inducing a junction in n-type InxGa(1-x)N
}

Joshua J. Williams, Todd L. Williamson, Mark A. Hoffbauer, Alec M. Fischer, Stephen M. Goodnick et al.

Citation: J. Vac. Sci. Technol. B 31, 03C127 (2013); doi: 10.1116/1.4797489

View online: http://dx.doi.org/10.1116/1.4797489

View Table of Contents: http://avspublications.org/resource/1/JVTBD9/v31/i3

Published by the AVS: Science \& Technology of Materials, Interfaces, and Processing

\section{Related Articles}

Temperature stability of high-resistivity GaN buffer layers grown by metalorganic chemical vapor deposition J. Vac. Sci. Technol. B 31, 051208 (2013)

Discrepancies in the nature of nitrogen incorporation in dilute-nitride $\mathrm{GaSbN}$ and GaAsN films

J. Vac. Sci. Technol. B 31, 051206 (2013)

On the environmental stability of $\mathrm{ZnO}$ thin films by spatial atomic layer deposition

J. Vac. Sci. Technol. A 31, 061504 (2013)

Growth of high quality $\mathrm{ZnO}$ thin films with a homonucleation on sapphire

J. Vac. Sci. Technol. B 31, 041206 (2013)

Tin oxide atomic layer deposition from tetrakis(dimethylamino)tin and water

J. Vac. Sci. Technol. A 31, 061503 (2013)

\section{Additional information on J. Vac. Sci. Technol. B}

Journal Homepage: http://avspublications.org/jvstb

Journal Information: http://avspublications.org/jvstb/about/about_the_journal

Top downloads: http://avspublications.org/jvstb/top_20_most_downloaded

Information for Authors: http://avspublications.org/jvstb/authors/information_for_contributors

\section{ADVERTISEMENT}

\section{Instruments for advanced science}
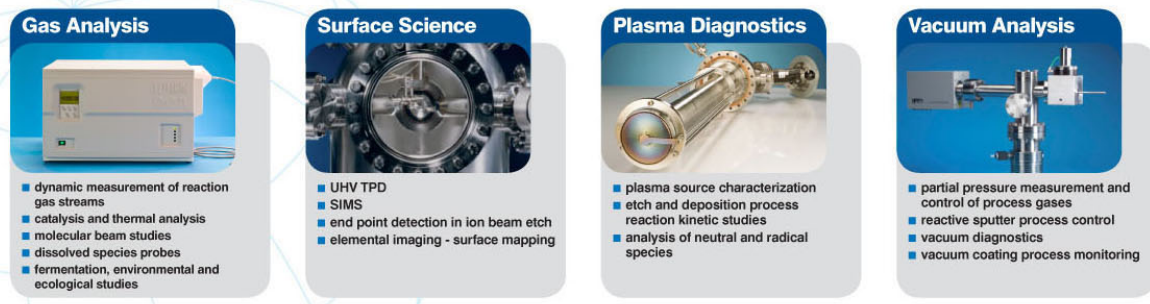

contact Hiden Analytical for further details

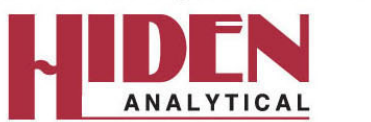

info@hideninc.com

www.HidenAnalytical.com

CLICK to view our product catalogue 


\title{
Inducing a junction in $n$-type $\ln _{x} G_{(1-x)} N$
}

\author{
Joshua J. Williams ${ }^{a}$ \\ Materials Science and Engineering, Arizona State University, PO Box 875706, Tempe, Arizona 85287-5706
}

Todd L. Williamson and Mark A. Hoffbauer

Chemistry Division, Los Alamos National Laboratory, PO Box 1663, MS J565, Los Alamos, New Mexico 87545

Alec M. Fischer

Department of Physics, Arizona State University, PO Box 871504, Tempe, Arizona 85287-1504

Stephen M. Goodnick, Nikolai N. Faleev, Kunal Ghosh, and Christiana B. Honsberg

Electrical Engineering, Arizona State University, PO Box 875706, Tempe, Arizona 85287-5706

(Received 26 November 2012; accepted 11 March 2013; published 10 April 2013)

\begin{abstract}
The pseudo-binary alloy of indium $(\mathrm{x})$ gallium $_{(1-\mathrm{x})}$ nitride has a compositionally dependent bandgap ranging from 0.65 to $3.42 \mathrm{eV}$, making it desirable for light emitting diodes and solar cell devices. Through modeling and film growth, the authors investigate the use of $\operatorname{In}_{\mathrm{x}} \mathrm{Ga}_{1-\mathrm{x}} \mathrm{N}$ as an active layer in an induced junction. In an induced junction, electrostatics are used to create strong band bending at the surface of a doped material and invert the bands. The authors report modeling results, as well as preliminary film quality experiments for an induced junction in $\mathrm{InGaN}$ by space charge effects of neighboring materials, piezoelectric effects, and spontaneous polarization. (C) 2013 American Vacuum Society. [http://dx.doi.org/10.1116/1.4797489]
\end{abstract}

\section{INTRODUCTION}

Concentrating photovoltaics systems are of increasing interest for large scale utility applications ${ }^{1}$ due to their potential for a cost of electricity comparable to other utility generation; a better match of electricity production to a typical load profile; and the ability to install large systems rapidly and reliably. A central requirement for broad viability of concentrated photovoltaics systems is that the solar cells have a high efficiency under concentration, with a roadmap target of $50 \%$ efficiency.

To achieve high efficiency, multiple solar cell junctions are series connected to form a tandem solar cell. Present tandem solar cells are based on materials closely lattice matched to GaAs and which also have band gaps close to the ideal. While over $40 \%$ efficiency under concentration ${ }^{2-5}$ has been demonstrated by several tandem solar cell approaches, these face increasing challenges in reaching the tandem solar cell roadmap target of $50 \%$ efficiency, and therefore materials as the III-nitrides, which overcome these challenges, are of increasing interest for solar cells. One of the most significant challenges is the difficulty in achieving high quality materials in the band gap range of $0.7-1.3 \mathrm{eV}$, which are compatible with the other solar cells in the tandem stack. Furthermore, as the number of junctions in the solar cell increases above three junctions in order to reach higher theoretical efficiencies, the growth of direct band gap materials over $2.0 \mathrm{eV}$ also introduces a limitation.

The theoretical efficiency of a solar cell as calculated from thermodynamic considerations depends primarily on its band gap. How close a solar cell comes to this in practice depends primarily on the recombination mechanics,

${ }^{\text {a)} E l e c t r o n i c ~ m a i l: ~ j j w i l l i 6 @ a s u . e d u ~}$ including recombination in the bulk, at the surfaces or interfaces and at the contacts.

The value of the optimum band gap depends on the spectrum (terrestrial air mass (AM) 1.5 or AM0), the optical concentration and the number of junctions in the solar cell stack. Table I gives the theoretical efficiencies for three junction (3J) and four junction (4J) solar cells. The optimum 3J band gaps are shown in Table I, for the AM1.5 spectrum and moderate concentration. Changes in assumptions about the incident spectrum, temperature, and concentration may give small changes in the optimum band gaps.

The materials that have band gaps closest to the optimum ones listed in Table I and that are also closely lattice matched to each other are alloys in the GaInAs or GaInP materials systems, typically grown monolithically on a $\mathrm{Ge}$ substrate. Several growth and material combinations have exceeded $40 \%$ efficiency under concentration. These approaches are based on materials lattice matched or closely lattice matched to GaAs; the variations are due to different approaches to achieve materials with high minority carrier lifetimes and with the optimum band gaps. The growth and material approaches include: growth of materials lattice matched or slightly metamorphic to GaAs (with the GaAs band gap as nonideal) ${ }^{2}$ the use of dilute nitride (GaInAsN) $;^{5}$ bifacial growth on the GaAs wafer, using a low band gap GaInAs layer on the rear of the GaAs substrate; ${ }^{4}$ and metamorphic inverted structures, where high band gap solar cells are grown first, necessitating removing the substrate before use as a solar cell. ${ }^{3}$

Despite the high efficiencies using these approaches, approaches that allow higher efficiency are necessary to reach the efficiency potential of tandem solar cells. The theoretical maximum efficiency as derived from thermodynamics using detailed balance formulation is $59.9 \%$ for three solar cells (3J) under AM1.5D and $300 \times$ concentration. The 
TABLE I. Band gaps and efficiencies for 3J and 4J using AM1.5D.

\begin{tabular}{lcccccc}
\hline \hline Solar cell structure & $\begin{array}{c}\text { Optical } \\
\text { concentration }\end{array}$ & $\begin{array}{c}\text { EG1 } \\
(\mathrm{eV})\end{array}$ & $\begin{array}{c}\text { EG2 } \\
(\mathrm{eV})\end{array}$ & $\begin{array}{c}\text { EG3 } \\
(\mathrm{eV})\end{array}$ & $\begin{array}{c}\text { EG4 } \\
(\mathrm{eV})\end{array}$ & $\begin{array}{c}\text { Eff } \\
(\%)\end{array}$ \\
\hline Detailed balance 3J & $300 \times$ & 0.7 & 1.18 & 1.75 & - & 59.9 \\
Lattice matched 3J & $300 \times$ & 0.66 & 1.42 & 1.89 & - & 49.9 \\
Experimental 3J & $240 \times$ & 0.68 & 1.43 & 1.85 & - & 40.7 \\
Detailed balance 4J & $300 \times$ & 0.69 & 1.04 & 1.44 & 1.93 & 63.5 \\
\hline \hline
\end{tabular}

maximum efficiency is increased by adding additional junctions, and for an "infinite" number of junctions the efficiency under maximum possible concentration is $86.8 \%$. The difficulty in finding materials both lattice matched to GaAs and with optimum band gaps increases with $4 \mathrm{~J}$ or $5 \mathrm{~J}$ devices. As shown in Table I, with $4 \mathrm{~J}$ devices, a $1 \mathrm{eV}$ material with good material properties is essential; with $5 \mathrm{~J}$ and higher numbers of junctions (Table II), the top or top two solar cells require band gaps above $2.0 \mathrm{eV}$, presently difficult with existing material systems.

A fundamentally different approach to tandem devices is to use low concentration with a simpler, lower cost solar cell structure, consisting of two junctions. The optimum band gaps for a $2 \mathrm{~J}$ tandem are 1.1 and $1.9 \mathrm{eV}$, meaning that $\mathrm{Si}$ can be used as a substrate if a suitable top junction material can be found.

One possibility for both ultrahigh efficiency tandems and tandems on silicon is the indium gallium nitride $\left(\operatorname{In}_{1-x} \mathrm{Ga}_{\mathrm{x}} \mathrm{N}\right.$ or InGaN) alloy material system, which ranges from $\sim 0.7 \mathrm{eV}(\mathrm{InN})$ to $\sim 3.4 \mathrm{eV}(\mathrm{GaN})$ with varying mole fractions of metal. ${ }^{6} \mathrm{GaN}$ is prevalent in many technologies, including high electron mobility transistors and white light emitting diodes. InN is not as well understood as $\mathrm{GaN}$, and currently only has technological significance in small alloying percentages with $\mathrm{GaN}$ for blue optoelectronic devices. ${ }^{7}$

The use of the III-nitride system for solar cells requires InGaN material. However, there are well known material challenges associated with device quality InGaN. These challenges include producing low defect density material, uniform indium incorporation into the grown film, a thermodynamic miscibility gap, and high residual n-type background carrier concentration. Increasing indium percentage exacerbates all of these problems. ${ }^{8}$ In recent years, research by many groups has addressed many of these challenges. ${ }^{8-10}$ However, growth of InGaN with p-type characteristics with sufficient quality for devices continues to be a barrier to achieving high quality InGaN devices with high mole fraction In material.

While the InGaN material system can be used in many different configurations, an initial approach is to focus on

TABLE II. $\mathrm{In}_{\mathrm{x}} \mathrm{Ga}_{1-\mathrm{x}} \mathrm{N}$ composition for tandem junctions.

\begin{tabular}{lccc}
\hline \hline Junction ID & Top 1 of 5 & 2nd to top of 6 & Top 1 of 6 \\
\hline Ideal $\mathrm{E}_{\mathrm{G}}$ & $2.1 \mathrm{eV}$ & $1.7 \mathrm{eV}$ & $2.3 \mathrm{eV}$ \\
$\mathrm{x}$ at $\mathrm{E}_{\mathrm{G}}$ & $\sim 38 \%$ & $\sim 52 \%$ & $\sim 32 \%$ \\
\hline \hline
\end{tabular}

band gaps on the order of $2.0 \mathrm{eV}$; material in this range is better developed, it addresses the need for higher band gaps for higher junction tandems; and it can also be used for silicon tandem devices. The In mole fractions for the top or top two junctions (in the case of a $6 \mathrm{~J}$ tandem) are shown in Table II. The central challenges in realizing a $2 \mathrm{eV}$ InGaN solar cell relate to designing a junction without p-type doping and realizing sufficient material quality. We can avoid this technological hurdle through device architecture.

The standard method for this, a heterojunction, is not suitable for lower band gap InGaN solar cells since the spontaneous and piezoelectric polarizations create device limiting band spikes, which prevent current collection under light bias near the maximum power point. ${ }^{11}$ Therefore, we propose an induced junction device that will use the polarization effects to invert a region of the n-type InGaN, creating a very thin (on the order of $10 \mathrm{~nm}$ ) region of p-type material. The induced junction is created when electric fields from electrostatics or polarizations strongly bend the bands of an active material and invert the surface. ${ }^{12}$ This means that with respect to the Fermi level an n-type material will appear to be locally p-type. A schematic of such a band diagram is shown Fig. 1. The realization of this design requires control and measurement of the strain and piezoelectric properties, and design of the interface to accommodate both interface inversion and transport across the interface.

In this paper, we present the design, the material requirements, and experimental investigation of materials that can be used to realize an induced junction solar cell. Section II presents the modeling of an induced junction system, taking into account strain, material quality, and piezoelectric properties. Section III presents the growth of InGaN with a large indium mole fraction to achieve band gaps in the $2 \mathrm{eV}$ range, and the analysis of the material and devices.

\section{MODELING METHODS}

An induced junction achieves carrier collection by creating a strongly inverted region at the interface of an n-type InGaN layer. A schematic of the device is shown in Fig. 2.

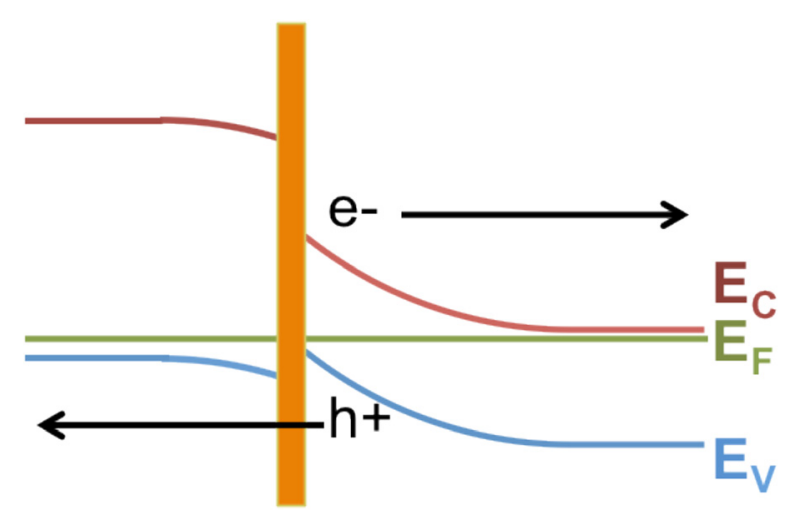

FIG. 1. (Color online) Schematic representation of an induced junction. The material on the left is a p-type window layer. The layer in the middle is an extremely thin high bandgap material. The material on the right is the absorber and actual induced junction. 


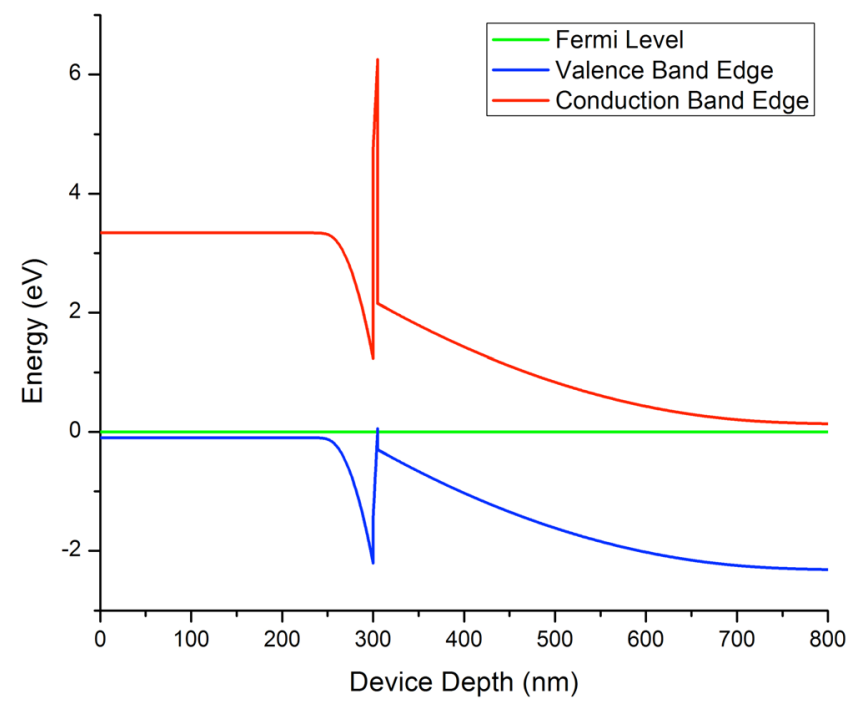

FIG. 2. (Color online) Results from Sentaurus for band alignments of a GaN/ $\mathrm{AlN} / \mathrm{In}_{0.25} \mathrm{Ga}_{0.75} \mathrm{~N}$. Device is at equilibrium.

InGaN is the only active (both optically and electrically) device layer; while the other layers are primarily responsible for carrier extraction and influencing the band bending of the InGaN layer. Thus, while the structure appears similar to a heterojunction, its transport and recombination properties are not dependent on the GaN layers (or other high band gap layer). The device is a minority carrier device with the transport and carrier collection mechanism significantly different from standard metal-insulator-semiconductor (MIS) based diodes. The operation resembles strongly to that of a minority carrier MIS devices used in solar cells. The strong inversion reduces the interface recombination and assists in the overall carrier transport through the i-region and to the top contact by lowering the effective barrier the carriers encounter at the heterointerface.

It has several advantages over a pn junction or heterojunction. The absence of the heavily doped emitter results in the elimination of the doping-induced degradation of minority carrier lifetimes. This in addition to being a thin junction $(50-100 \mathrm{~nm})$, reduce carrier recombination in the inverted region. Furthermore, the band bending at the interface reduces the effective surface/interface recombination velocity and makes the device less dependent on interface quality, both increasing efficiency and decreasing the material requirements for the high band gap layer.

The analysis of band diagram under thermal equilibrium (equilibrium band diagram) illustraets the operation of a device, particularly regarding the transport across the interfaces. The equilibrium band diagram is simulated with a computer model developed in the commercial simulator Sentaurus. Several of the important parameters of the model are described below to help better understand the equilibrium band diagram. The InGaN, AlN, and GaN layers are 500,5 , and $300 \mathrm{~nm}$ thick, respectively. The fraction of indium content in the InGaN layer is 0.25 . The $\mathrm{GaN}$ is $\mathrm{p}^{+}$ doped while the $\mathrm{InGaN}$ is $\mathrm{n}^{+}$doped to create effective carrier concentrations of $10^{16}$ holes $/ \mathrm{cm}^{3}$ and $10^{18}$ electrons/ $\mathrm{cm}^{3}$, respectively. Although Sentarus is capable of handling piezoelectric polarization internally, the developed model in the present structure cannot include strain and stress dependent polarization effects. The shortcoming is overcome by calculating the piezoelectric charges separately and introducing the calculated charge as sheet charge at each of the interfaces. The calculations assume fully strained layers and the equations (in Appendix) used for the calcultion of the piezoelectric charges are those reported by Chen et al. ${ }^{13}$

The equilibrium band diagram in Fig. 2 shows considerable band bending at the interface between InGaN and AIN. Due to band bending, the concentration of holes in the InGaN at the interface under thermal equilibrium is more than the n-type background doping in the quasi-neutral region, resulting in an inversion of the $\mathrm{InGaN}$ near the interface. The inversion region assists in the carrier transport mechansim across the heterointerface by lowering the effective barrier that carriers encounter at the heterointerface. The effective barrier is a function of both the band offset that is fixed and the band bending that is a function of applied potential. A lowering of the effective barrier influences both thermionic emission and tunneling transport mechanisms. Modeling performed by Ghosh et al. has demonstrated this effect in crystalline silicon-amorphous silicon interfaces. ${ }^{14}$

\section{EXPERIMENT METHODS}

$\mathrm{In}_{\mathrm{x}} \mathrm{Ga}_{1-\mathrm{x}} \mathrm{N}$ films and prototype films for InGaN based induced junction devices were grown by molecular beam epitaxy at Los Alamos National Laboratory. Films were grown on bare epi-ready c-plane sapphire substrates using thermal evaporators for group III metals and a proprietary neutral atom beam source (ENABLE) for nitrogen. Details on the ENABLE growth conditions have been reported previously. ${ }^{15-17}$ Films grown by this technique tend to be inherently nitrogen polar. Base pressure for the growth chamber were $\sim 10^{-10}$ Torr. Substrates were degassed at $\sim 900^{\circ} \mathrm{C}$ and prenitrided at $\sim 400^{\circ} \mathrm{C}$. Chamber pressures during growth were $\sim 10^{-5}$ Torr. A quality GaN$\mathrm{In}_{\mathrm{x}} \mathrm{Ga}_{1-\mathrm{x}} \mathrm{N}$ structure was grown as a control, and a second structure was grown comprised of $\mathrm{GaN}-\mathrm{AlN}-\mathrm{In}_{\mathrm{x}} \mathrm{Ga}_{1-\mathrm{x}} \mathrm{N}$ both with $\mathrm{x}=0.25$. The structures' film details are presented in Table III.

Crystal properties of structures were analyzed by highresolution $\mathrm{X}$-ray diffraction. Photoluminescence (PL) was performed to determine the band gap energy. Spectra intensity was calibrated by removing the background and also by considering the quantum efficiency of the PL system. Both techniques were used to determine the degree of compositional splitting.

TABlE III. Sample growth parameters.

\begin{tabular}{|c|c|c|c|c|}
\hline Sample \# & Layer \# & Description & Nominal temp. & Thickness \\
\hline \multirow[t]{4}{*}{ ENB-775 } & 0 & Sapphire substrate C-plane & N/A & $\sim 500 \mu \mathrm{m}$ \\
\hline & 1 & GaN buffer & $750^{\circ} \mathrm{C}$ & $\sim 300 \mathrm{~nm}$ \\
\hline & 2 & $\mathrm{In}_{0.25} \mathrm{Ga}_{0.75} \mathrm{~N}$ buffer & $550^{\circ} \mathrm{C}$ & $\sim 100 \mathrm{~nm}$ \\
\hline & 3 & $\mathrm{In}_{0.25} \mathrm{Ga}_{0.75} \mathrm{~N}$ & $600^{\circ} \mathrm{C}$ & $\sim 750 \mathrm{~nm}$ \\
\hline \multirow[t]{4}{*}{ ENB-746 } & 0 & Sapphire substrate C-plane & N/A & $\sim 500 \mu \mathrm{m}$ \\
\hline & 1 & GaN buffer/Film & $800^{\circ} \mathrm{C}$ & $\sim 300 \mathrm{~nm}$ \\
\hline & 2 & AlN thin Film & $850^{\circ} \mathrm{C}$ & $\sim 5 \mathrm{~nm}$ \\
\hline & 3 & $\mathrm{In}_{0.25} \mathrm{Ga}_{0.75} \mathrm{~N}$ active layer & $550^{\circ} \mathrm{C}$ & $\sim 500 \mathrm{~nm}$ \\
\hline
\end{tabular}




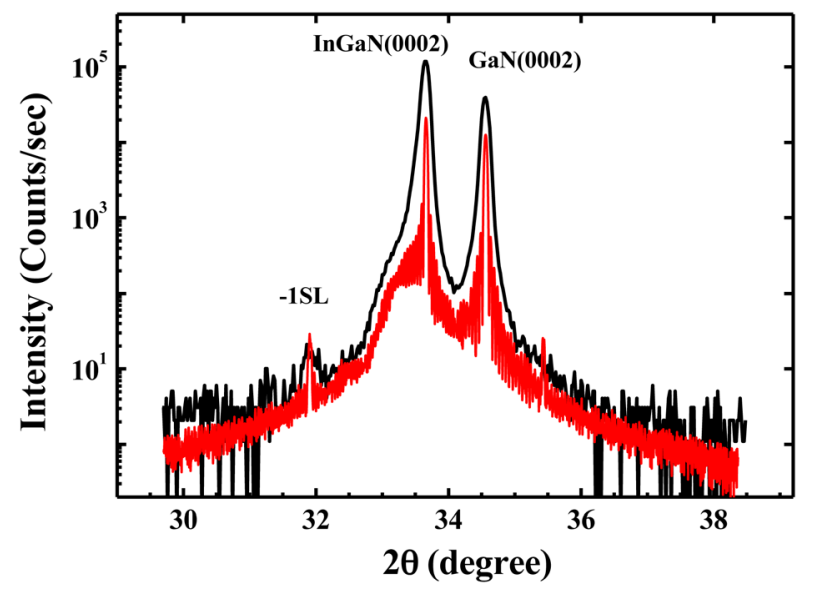

FIG. 3. (Color online) Double crystal $\omega-2 \theta$ rocking curves of ENB-775 (rounded peaks with greater intensity-experimental, sharper peaks with less intensity - calculated) in the vicinity of InGaN and GaN (0002) reflections. - 1SL peak indicates an unintentional modulation of In composition in InGaN layer with the period $\sim 5.5 \mathrm{~nm}$. The shoulder on the left side of InGaN (0002) peak is related to the small gradient of composition in InGaN layer on the initial stage of deposition.

Characterization of structure crystal quality was performed by XRD. Analysis of diffractions patterns from an $\omega-2 \theta$ rocking curve provides information on compositional splitting, super-latticing, and compositions of alloys. Diffraction patterns of triple-crystal $\omega$ rocking curve scans are used in conjunction with models developed to estimate defect densities. ${ }^{18-20}$

Analysis of ENB-775 $\omega-2 \theta$ rocking curves on Fig. 3 shows the existence of gradients of indium composition in the InGaN film ranging from $\mathrm{x} \approx 0.34$ to $\mathrm{x} \approx 0.26$. This is likely related to the InGaN buffer layer grown at a $50{ }^{\circ} \mathrm{C}$ temperature difference. There is a super latticing peak that arises from unintended indium composition modulation at the main part of the epitaxial layer. The period of modulation is $\sim 5.25 \mathrm{~nm}$. Also, there is a lack of a InN peak indicating no In decomposition. The triple-crystal $\omega$ scan of ENB-775 in Fig. 4 shows defect densities in both the $\mathrm{GaN}$ and $\mathrm{InGaN}$ layers. The GaN film has a full width half maximum $(\mathrm{FWHM})=740 \mathrm{arc} / \mathrm{s}$. This gives a density of dislocation

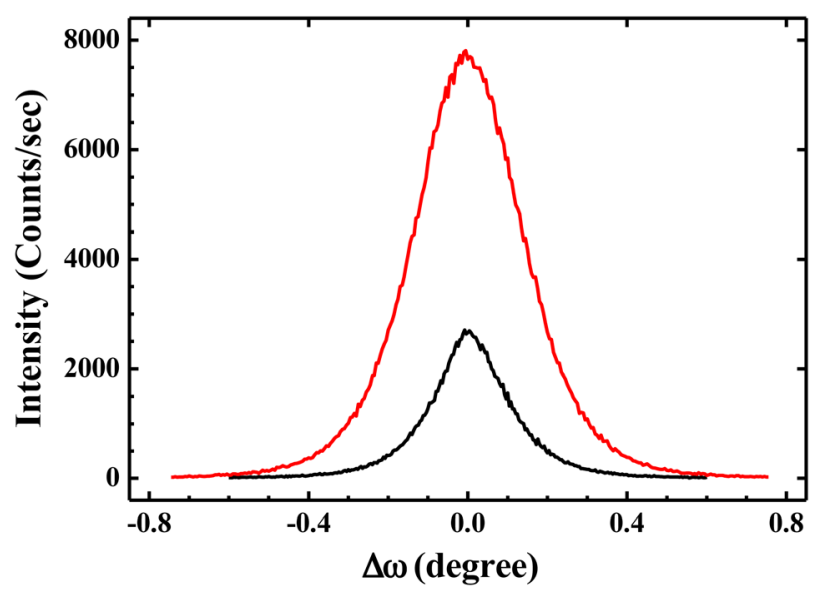

FIG. 4. (Color online) Triple crystal $\omega$ rocking curves of ENB-775, measured on the maximum of $\mathrm{GaN}(0002)$ (weaker) and $\mathrm{InGaN}(0002)$ (stronger) peaks. FWHM of these peaks is 740 and $1140 \mathrm{arc} / \mathrm{s}$, accordingly.

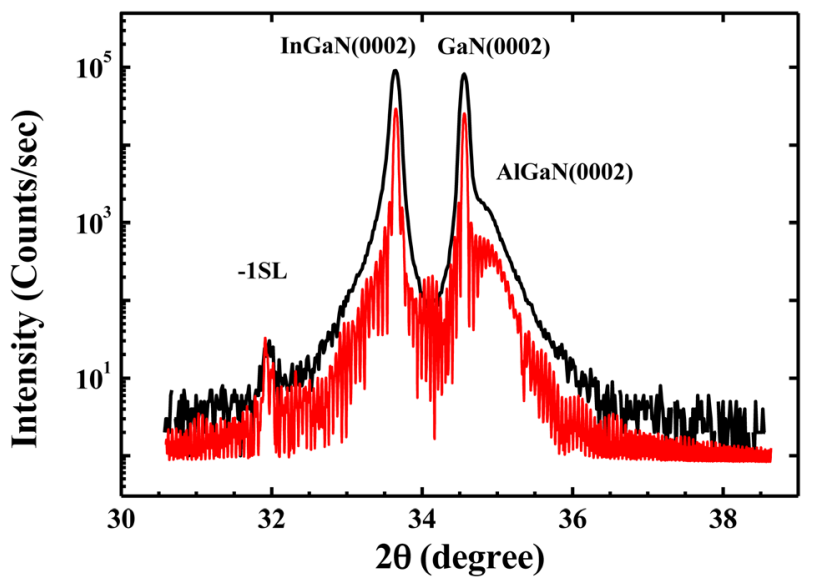

FIG. 5. (Color online) Double crystal $\omega$-2 $\theta$ rocking curves of ENB-746 (rounded peaks with greater intensity-experimental, sharper peaks with less intensity - calculated) in the vicinity of InGaN and $\mathrm{GaN}$ (0002) reflections. -1SL peak indicates an unintentional modulation of In composition in InGaN layer with the period $\sim 5.35 \mathrm{~nm}$. The shoulder on the right side of $\mathrm{GaN}$ (0002) peak is related to the thin $\mathrm{AlGaN}$ layer, created on the top of the $\mathrm{GaN}$ buffer layer.

loops $\sim 5.6 \times 10^{8} / \mathrm{cm}^{2}$. The $\operatorname{In}_{0.26} \mathrm{Ga}_{0.74} \mathrm{~N}$ film has $\mathrm{FWHM}=1135 \mathrm{arc} / \mathrm{s}$. This gives a density of dislocation loops $\sim 1.35 \times 10^{9} / \mathrm{cm}^{2}$. The $\mathrm{In}_{0.34} \mathrm{Ga}_{0.66} \mathrm{~N}$ gradient film has $\mathrm{FWHM}=2340$ arc sec. This gives a density of dislocation loops in this area $\sim 5.6 \times 10^{9} / \mathrm{cm}^{2}$.

ENB-746 shows similar characteristics with respect to indium composition gradient and super latticing modulation spacing, as shown in Figs. 5 and 6. Values for these are $\mathrm{x} \approx 0.26$ to $\mathrm{x} \approx 0.32$ and $5.35 \mathrm{~nm}$, respectively. It is unclear why there is compositional splitting in ENB-746; however, it is likely due to initial InGaN nucleation stages of growth on AlN, which is lattice mismatched with InGaN. They also, share a lack of InN phase separation. It appears that the intentional AlN layer is actually an $\mathrm{Al}_{\mathrm{X}} \mathrm{Ga}_{1-\mathrm{x}} \mathrm{N}$ layer with a compositional gradient corresponding to $\mathrm{x} \approx 0.33$ to $\mathrm{x} \approx 0.05$. Transmission electron microscopy (TEM) analysis will be needed to resolve this. The triple-crystal $\omega$ scan shows defect densities in both the GaN, "AlN," and InGaN layers. The $\mathrm{GaN}$ film has FWHM $=460$ arc sec. This gives a

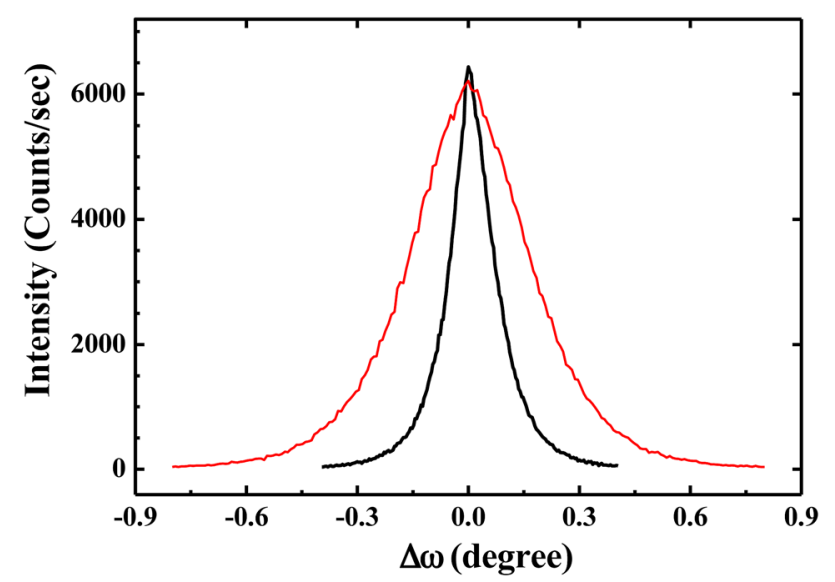

FIG. 6. (Color online) Triple crystal $\omega$ rocking curves of ENB-746, measured on the maximum of $\mathrm{GaN}(0002)$ (sharper) and $\mathrm{InGaN}(0002)$ (broader) peaks. FWHM of these peaks is 455 and 1265 arc/s, accordingly. 


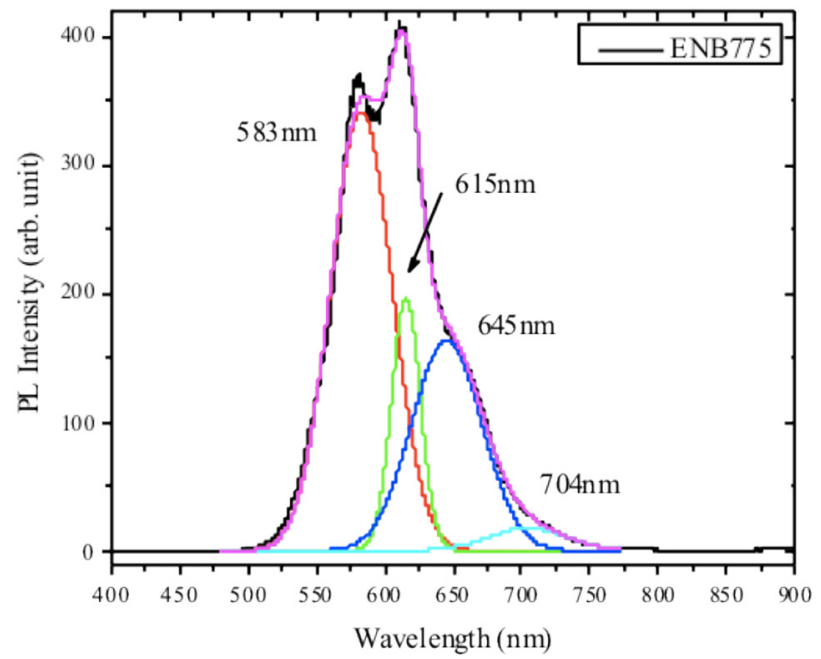

FIG. 7. (Color online) Photoluminescence of ENB-775. Probing laser power of $7 \mathrm{~mW}$. Collection time was $1 \mathrm{~s}$. Gaussian peaks are estimated deconvolutions of original spectrum.

density of dislocation loops $\sim 1.5 \times 10^{4} / \mathrm{cm}\left(2.2 \times 10^{8} / \mathrm{cm}^{2}\right)$. The $\mathrm{In}_{0.26} \mathrm{Ga}_{0.74} \mathrm{~N}$ film has $\mathrm{FWHM}=1290$ arc sec. This gives a density of dislocation loops $\sim 4.1 \times 10^{4} / \mathrm{cm}$ $\left(1.7 \times 10^{9} / \mathrm{cm}^{2}\right)$. The "AlN" film has FWHM $=490$ arc sec. This gives a density of dislocation loops $\sim 1.6 \times 10^{4} / \mathrm{cm}$ $\left(2.2 \times 10^{9} / \mathrm{cm}^{2}\right)$.

PL measurements of the samples were performed with a $325 \mathrm{~nm}$ wavelength $\mathrm{HeCd}$ laser to analyze the bandgap for each film. The PL results and the separation of the PL peaks into separate peaks are shown in Figs. 7 and 8, respectively. The multiple peaks in the PL graphs are indicative of compositional variations in the films, which are in agreement with the results from XRD. These films show PL peaks at $\sim 580 \mathrm{~nm}(\sim 2.14 \mathrm{eV})$ and $\sim 615 \mathrm{~nm}(\sim 2.08 \mathrm{eV})$ with some lower intensity peaks at even longer wavelengths. The energy values of these peaks are red-shifted compared to the PL emission expected from InGaN material with composition measured from the XRD. For example, analysis of the

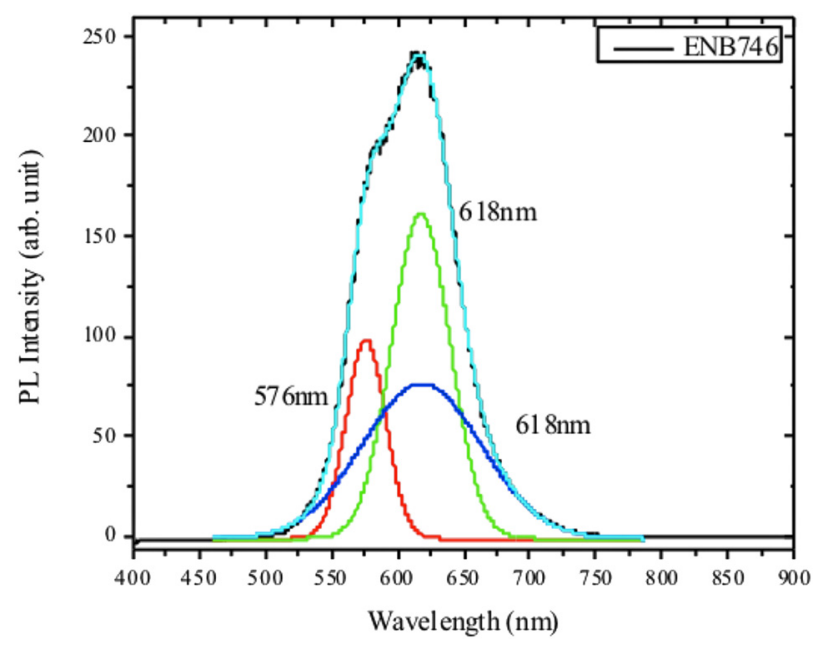

FIG. 8. (Color online) Photoluminescence of ENB-746. Probing laser power of $7 \mathrm{~mW}$. Collection time was $1 \mathrm{~s}$. Gaussian peaks are estimated deconvolutions of original spectrum.
XRD data using a reported value of $1.36 \mathrm{eV}$ (Ref. 21) for the bowing parameter, gives $\mathrm{x} \approx 0.26$ to $\mathrm{x} \approx 0.32$, corresponding to peaks expected at $\sim 510 \mathrm{~nm}(\sim 2.51 \mathrm{eV})$ and $\sim 570 \mathrm{~nm}$ $(\sim 2.24 \mathrm{eV})$, respectively. Thus, it seems that the photoluminescence from these films is red-shifted due to either strain or defects.

\section{SUMMARY AND CONCLUSIONS}

In summary, we have modeled the effects of spontaneous polarization and piezoelectric field due to strain as a means for inducing a junction in indium gallium nitride alloys. Experimentally, we have determined that the growth of such films and especially an aluminum nitride barrier layer does not severely hamper standard material properties. Future work will include refinement of the Sentaurus model to describe charge transport and solve iteratively for piezoelectric/strain coupling. Future characterization will further examine compositional data and dislocation densities through TEM, and actual band effects between nitride layers using electron holography.

\section{ACKNOWLEDGMENTS}

This material was based upon work primarily supported by the Engineering Research Center Program of the National Science Foundation and the Office of Energy Efficiency and Renewable Energy of the Department of Energy under NSF Cooperative Agreement No. EEC-1041895. Any opinions, findings and conclusions or recommendations expressed in this material are those of the author(s) and do not necessarily reflect those of the National Science Foundation or Department of Energy.

\section{APPENDIX}

$$
\begin{aligned}
& \varepsilon=\left(a_{\text {substrate }}-a_{\text {Layer }}\right) / a_{\text {Layer }} \\
& P_{p z}(\mathrm{AlN})=-1.808 \cdot \varepsilon+5.624 \cdot \varepsilon^{2} \quad \text { for } \varepsilon<0 \\
& P_{p z}(\mathrm{AlN})=-1.808 \cdot \varepsilon+7.888 \cdot \varepsilon^{2} \quad \text { for } \varepsilon>0 \\
& P_{p z}(\mathrm{GaN})=-0.918 \cdot \varepsilon+9.541 \cdot \varepsilon^{2} \\
& P_{p z}(\mathrm{InN})=-1.373 \cdot \varepsilon+7.559 \cdot \varepsilon^{2} \\
& P_{p z}\left(\mathrm{Al}_{x} \operatorname{In}_{y} \mathrm{Ga}_{1-x-y} \mathrm{~N}\right)=P_{p z}(\mathrm{AlN}) x+P_{p z}(\operatorname{InN}) y \\
& +P_{p z}(\mathrm{GaN})(1-x-y) \\
& P_{s p}\left(\mathrm{Al}_{x} \mathrm{Ga}_{1-x} \mathrm{~N}\right)=-0.090 x-0.034(1-x) \\
& +0.019 x(1-x) \\
& P_{s p}\left(\mathrm{Al}_{x} \operatorname{In}_{1-x} \mathrm{~N}\right)=-0.090 x-0.042(1-x) \\
& +0.071 x(1-x) \\
& P_{s p}\left(\operatorname{In}_{x} \mathrm{Ga}_{1-x} \mathrm{~N}\right)=-0.042 x-0.034(1-x) \\
& +0.038 x(1-x) \\
& \sigma\left(P_{s p}+P_{p z}\right)=\left[P_{s p}(\text { bottom })+P_{p z}(\text { bottom })\right] \\
& -\left[P_{s p}(\text { top })+P_{p z}(\text { top })\right] \text {. }
\end{aligned}
$$


${ }^{1}$ R. R. King et al., Prog. Photovolt.: Res. Appl. 20, 801 (2012).

${ }^{2}$ R. R. King, D. C. Law, K. M. Edmondson, C. M. Fetzer, G. S. Kinsey, H. Yoon, R. A. Sherif, and N. H. Karam, Appl. Phys. Lett. 90, 183516 (2007).

${ }^{3}$ J. F. Geisz et al., Appl. Phys. Lett. 93, 123505 (2008).

${ }^{4}$ P. Chiu, S. Wojtczuk, X. Zhang, C. Harris, D. Pulver, and M. Timmons, in 2011 37th IEEE Photovoltaic Specialists Conference (PVSC), Seattle, WA, 2011, pp. 000771-000774.

${ }^{5} \mathrm{M}$. Wiemer, V. Sabnis, and H. Yuen, in Proceedings of SPIE High and Low Concentrator Systems for Solar Electric Applications VI, San Diego, CA, 2011, pp. 810804.

${ }^{6}$ J. Wu, W. Walukiewicz, K. M. Yu, J. W. Ager III, E. E. Haller, H. Lu, W. J. Schaff, Y. Saito, and Y. Nanishi, Appl. Phys. Lett. 80, 3967 (2002).

${ }^{7}$ F. A. Ponce and D. P. Bour, Nature 386, 351 (1997).

${ }^{8}$ J. Phillip et al., Laser Photon. Rev. 1, 307 (2007).

${ }^{9}$ M. Moseley, J. Lowder, D. Billingsley, and W. A. Doolittle, Appl. Phys. Lett. 97, 191902 (2010).

${ }^{10}$ W. Walukiewicz, R. E. Jones, S. X. Li, K. M. Yu, J. W. Ager III, E. E. Haller, H. Lu, and W. J. Schaff, J. Cryst. Growth 288, 278 (2006).

${ }^{11}$ E. Trybus, G. Nomkoong, W. Henderson, S. Burnham, W. A. Doolittle, M. Cheung, and A. Cartwright, J. Cryst. Growth 288, 218 (2006).
${ }^{12}$ K. Ghosh, C. J. Tracy, S. Herasimenka, C. Honsberg, and S. Bowden, in 2010 35th IEEE Photovoltaic Specialists Conference (PVSC), Honolulu, HI, 2010, pp. 001383-001386.

${ }^{13}$ J.-R. Chen, C.-H. Lee, T.-S. Ko, Y.-A. Chang, T.-C. Lu, H.-C. Kuo, Y.-K. Kuo, and S.-C. Wang, J. Lightwave Technol. 26, 329 (2008).

${ }^{14}$ K. Ghosh, S. Bowden, and C. Tracy, Phys. Status Solidi A 210, 413 (2013).

${ }^{15}$ T. L. Williamson, A. L. Salazar, J. J. Williams, and M. A. Hoffbauer, Phys. Status Solidi C 8, 2098 (2011).

${ }^{16}$ N. Miller, R. E. Jones, K. M. Yu, J. W. Ager, Z. Liliental-Weber, E. E. Haller, Walukiewicz, T. L. Williamson, and M. A. Hoffbauer, Phys. Status Solidi C 5, 1866 (2008).

${ }^{17}$ T. L. Williamson, J. J. Williams, J. C. D. Hubbard, and M. A. Hoffbauer, J. Vac. Sci. Tech. D 29, 03C132 (2011).

${ }^{18}$ J. E. Ayers, Heteroepitaxy of Semiconductors: Theory, Growth and Characterization (CRC, New York, 2007), pp. 301-312.

${ }^{19}$ J. E. Ayers, J. Cryst. Growth 135, 71 (1994).

${ }^{20}$ N. Faleev, H. Lu, and W. J. Schaff, J. Appl. Phys. 101, 093516 (2007).

${ }^{21}$ P. G. Moses and C. G. Van de Walle, Appl. Phys. Lett. 96, 021908 (2010). 